\title{
Acute Flaccid Paralysis Surveillance system Evaluation, Oyo state, Nigeria; 2008-2014
}

\author{
Maureen O. Anyanwu* \\ Epidemiology and Medical statistics, Nigeria Field Epidemiology and Laboratory Training Programme/University of Ibadan, \\ Ibadan/Abuja, Nigeria
}

\section{Objective}

We evaluated the AFP surveillance system in Oyo State to assess its attributes and determine if it was meeting its set objectives.

\section{Introduction}

In September, 2015, Nigeria was delisted from the list of polio endemic countries globally. To be certified polio free, the country must attain and maintain certification standard Acute Flaccid Paralysis (AFP) surveillance for additional two-years. In Oyo State, no case of Wild Polio Virus (WPV) has been reported since February, 2009.

\section{Methods}

We used the Centre for Disease Control and Prevention updated guidelines for evaluating public health surveillance system. We conducted a retrospective review of AFP surveillance data between $1^{\text {st }}$ January, 2008 and $31^{\text {st }}$ December, 2014. We conducted in-depth interviews with identified stakeholders. Semi-structured questionnaires were administered to Disease Surveillance and Notification Officers (DSNOs) and AFP focal persons. Univariate analysis was performed by calculating frequencies, means and proportions using Microsoft Excel 2010.

\section{Results}

The case definition of AFP and the tools for reporting are simple. Of the 897 AFP cases detected during the period under review (2008-2014), 20 (2.2\%) were laboratory confirmed WPV. The sensitivity of the system between 2008 and 2014 measured by the Annualized Non-Polio AFP (NPAFP) rate was consistently above the target. of $\geq 2 / 100,000$ population (Mean $=3.96$, Standard deviation (SD): 0.48). The mean NPAFP rate for underperforming LGAs during the review period was 1.6, SD: 0.31. The mean Stool adequacy and Timeliness were $91.43 \%$ (SD: 18.3 ) and 91.3\% (SD: 20.3) above the target of $\geq 80 \%$ respectively. The mean Data quality was $90 \%$ (target is $\geq 90$; SD: 3.8). Positive Predictive Value (PVP) was $2 \%$ (2008 -2009), and 0\% in 2010-2014.

\section{Conclusions}

The Oyo State AFP surveillance system is simple, flexible, sensitive and meeting its set objectives. However, PVP was low and the system's operating conditions are not stable. All the LGAs, at one point during the period under review did not meet the NPAFP and NPENT rates. We recommended that more logistic support should be provided for non-performing LGAs to improve case reporting, investigation, and response. DSNOs should be re -sensitized on reverse cold chain, so as to improve the NPENT rate

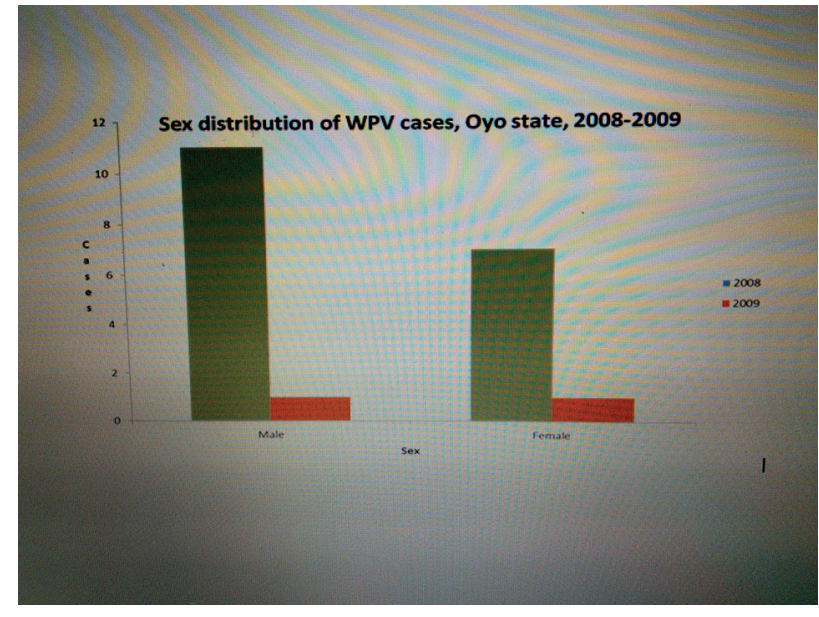

Keywords

Surveillance; Evaluation; Wild polio virus; Nigeria

\section{Acknowledgments}

Nigeria Field Epidemiology and laboratory Training Programme African Field Epidemiology Network

Centre for Disease Control, Atlanta, USA

Oyo State Ministry of Health

\section{*Maureen O. Anyanwu}

E-mail: maureenanyanwu23@yahoo.com 